\title{
Human Rights Violations in African Traditional Religion: The Masquerade Example.
}

\author{
Rev Fr Dr Christian O. Ele, Ph.D. \\ General Studies Division \\ Enugu State University of Science and Technology \\ Agbani, Enugu State \\ Nigeria
}

\begin{abstract}
This paper discusses Human Rights Violations in African Traditional Religion with a conscious focus on its masquerade administration. At its face value, masquerades are understood to represent entertainment and visitations by the spirits from the land of the dead. However, the contemporary trends show that masquerade institution is shrouded in secrecy known only to the members of the cult. On the outside, they violate the freedoms and rights of people with only flimsy a reason that it is people's culture. The bad effects of its practice outweigh its positive dimensions in today's world. The findings of this paper reveal, among others, that masked men who make others believe they are spirits have imposed on the larger society the burdens of atrocities which public responsibility demands that they must be treated with every sense of urgency and seriousness in order to put an end to the evil consequences of their operations. No one has any rights to violate the rights of others. In fact, one's rights stops where the other's begins. The challenges of masquerade culture include pastoral, cultural, economic, security, moral, social and political issues to mention but these few. The methodology employed in this work is historic-descriptive as the masquerades have been studied as a cultural practice with special interest on its human rights violations.
\end{abstract}

Keywords: Human rights, Violations, African Traditional Religion, Masquerade and Masquerade Administration.

\section{Introduction}

Masquerade (Мтиопwu, Mmanwu, Ma) is a vital aspect of African Traditional Religion. It is strongly believed by the practitioners of this faith that masquerades are spirits that come intermittently to visit the living with punishment for the evil persons or reward for the good ones. It also expresses the relationship which the secular has with the sacred in seasonal interactive sessions. These spiritual visitors also appear during festivals such as new yam festival, specific religious rituals like funerals, disputes such as land and other social needs like coronation of kings and in another moment to ensure there is order and discipline like to queue up in streams or other places with confusion potentials or to warn criminals to desist from perpetrating evil.

MasqueradesinIgbo culture include Ekpe, Adada, Oshimili, Okporompi, Mmonwuljele, Ekwe, Ulaga, Akataka, Akatakpa, Onyenwe al', Ogaeze, Enyanwu, Omabe(Oriokpa, Otunju), Edi Ogbene, Igele, echaricha ma, Odo, Elud'Ihe, Iyik'ite,ObodoAgu, OdoUgwu, Ojionu, Epedike, Ajulaka, Oshagenyi, Ajija, Mgbedike, et cetera. InAfrica, masquerades are grouped according to their nature or purpose. As some appear strictly at night, others can make their solemn or violent appearances during the day. Some of these masquerades by their nature are not seen by women. In Obukpa Religion, Akatakpa "operate usually during new yam festival and at the death of Onyishi" (Ozioko, 2005:52).On appearance, the presence of these masquerades in the wrong places for the right reasons by their definitions or in the right places for wrong reasons or for the right reasons but at wrong times have generated social crises in various communities across Africa. This study discovered that the masquerade institution is currently suffering from the internal violations of its sacredness and the consequences are manifested in the social negative values and immoral vices which it portrays. We take up the issue of initiation, for instance. Masquerade is a cult whose membership is prefaced by initiation and at some other more serious cases by divination. As Ugwu (1987:32) wrote, "For men, the masquerades are men dressed in masks but the very moment they are so dressed, they are no longer mere human beings but men raised above others to the spirit level worthy of worship and adoration. Men surprisingly worship these masked men with awe and fear that beat imagination. 
Women and children are told that the masquerades are dead persons who revisit the earth. Inspite of obvious proofs that the masquerades are ordinary human beings, women in their own pious credulity and sometimes out of fear of the men-folk worship and accept the masquerades as men and women of the spirit world." The initiation ceremony can be simple or complex; it all depends on the type of Mmonwu." An initiation, iba Mmanwu can take this nature: "A male child reaching the age of reason when he was considered capable of keeping secrets was initiated into the secret and cult of the masquerades. He was brought before a masquerade and the masquerade unmasked before the boy to the great astonishment and fright of the child who was ordered not to tell his mother what he saw, and that if he did, he would be killed."(Ugwu, 1987:33). Masquerade is not therefore a mere social show as its social value evidences in entertainment schemes and tourism actualities. It is vastly secretive, deeply spiritual and truly religious with grave aspects known only to the initiated. However, the uninitiated have taken over the institution as foundations or extensions of their business enterprises or a means of cover for their plural crimes. The rules are broken and the sacredness are violated and vacated. With the masks, crimes are committed on every masquerade season. The Nigerian Dailies and police crime diaries are awash with crimes which masquerades commit. The criminal aspects of this culture are linked with unfortunate violations of human rights. We shall be occupied with these violations in the next session.

\section{Human Rights Violations by Masquerades.}

Chukwudozie (1999:48) describes human rights as "the freedoms which all human beings naturally have from the moment they are born. They are rights or freedoms which we all enjoy automatically because we are human beings". The United Nations' Universal Declarations of Human Rights, 10 December 1948 and the chapter IV of the constitution of the Federal Republic of Nigeria of 1999 as amended recognize the right to life, right to movement, freedom of association and of religion, among others. These rights have been suffering gross abuses in the hands of masquerades in various communities across Africa. In Nsukka area of Enugu State, Nigeria the masquerades known mostly for these violations are the omabe (oriokpa) and Odo. We articulate the violations as follows:

(a)Freedom of Movement: In African traditional societies, masquerades have their village paths, village squares and other reserved areas for displays and performances. Today, they have gone into town, that is the urban cities and the high ways without respect for people's right to movement and the civilized values of urbanization. In some intra-urban roads, oriokpa conduct "stop and donate" money as if they were toll gate operators in the full glare of everybody. Movements are restricted on government built roads with impunity. They do not have the authorization of any legitimate body except their mischievous anchor on custom (omenala) and tradition (odinala) whose elastic legitimacy does not stretch to aberrations. The gruesome part of this menace does not at extortion, forceful donation but that innocent travelers and unsuspecting citizens have been flogged mercilessly. As written by Ozor (2015:2), " The complainants also reported that unsuspecting passers-by were being unduly harassed, maimed and even compelled to part with their hardearned money or face the wrath of the masquerades". In the same vein, it was gathered that on Thursday 12 July 2018 at Ogbodu-Aba, Enugu state, Nigeria two catholic priests were stopped, blocked and shamefully harassed by some masquerades and the slightest attempt by the priests to inquire what was amiss were greeted with rains of lashes and massive downpour of slaps from every side".(nationalhelm.co,2018:2). Earlier, on March 29, 2017 a group oforiokpa Nsukka beat a seminarian to coma as they blocked the Enugu road of Ugwuoye axis inside the urban city of Nsukka (Adegun, legit.ng,2017:1-3). Some victims have gone away from the scene of encounter with masquerades as travelers or indigenes with broken backs or heads tortured by these masked men. In this wake, some go to work, interviews for jobs, examinations, markets, social or religious functions late, a journey set out I time but for these masquerades. In Akwa Ibom State, Nigeria 10 members of the dreaded Ekpo masquerades were detained by the police for launching an attack on the police station. It was reported that the rampaging masquerades had blocked the Abak-Uyo dual carriageway, and began extorting money from road users. Matters went out of hand when the group of Ekpo attacked and injured some people. This ugly development led to the interventions of the security operatives (Ukwu, 2017:2). On this note, in Igala land Kogi State, Nigeria Adama (2013:179) wrote that "It is observed that in recent times some individuals mask themselves as masquerades into breakers of peace, law and order in the present society. They disguise into masquerades for stealing, looting, raping and retaliation. For example, in 2009 in Awo-ojuwo, a young man under the cloak of Inyanwuna masquerade waylays a young girl who was returning from catechism class. The masquerade went away with seven hundred naira forcefully collected from the girl. 
Secondly, in 2013 a military patrol team was attacked at Ejegbo by a group of Ukpokwumasquerades. One of the soldiers lost his life in the incident". The above narratives shoe that masquerades in contemporary Nigeria suppress the civilians and dare the Police and the Army.

(b)Freedom of Association/Right to one's choice of Religion: The frequent crises between the Church and the masquerade institutions stem largely from the latter's violation of the freedom of association and right to one's choice of religion. The Omabe and Odo masquerades could have "home coming"(udama) or "departure"(ulama) schedules on Sundays or Holy days of obligation. The fulcrum of the matter is that since women and children do not see their true nature of nakedness (odogbaoto, omabenkp'ta), then Church activities have to stop. The Holy Mother Church has resisted these attempts but with wounds and scars. At other times, Akatakpa could schedule its market ceremonies (izzashuama) and bans commercial activities for the day, days or native week. With these illegitimate infringements on people's rights, victims are separated from their legitimate groups, fellow worshippers or business associates. However, with the lawful resistance by the Church in various communities and the neglect of their calls for closure of markets by some business men, the crises are ongoing as some of them are sponsored by politicians for cheap political gains or by literate but fallen or weak Christians in the garb of neo-paganism.

\section{(c) Ritual Killing/Extra-judicial Killing}

Rights to life are one of most sublime inalienable human rights. One has to live before other rights would fall in place. History has it that some aspects of the masquerade institutional administration require ritual killing of human persons. Human sacrifice is needed to ensure that demonic forces of these masquerades are in perpetual activation. Again, some criminals, real or alleged are killed without trial by these masquerades. A lot of ugly events take place under the cover of masquerade cult. These atrocities are not easily known from generation to generation. One can now see why women and children are excluded from close relationships with the mmuonwu affairs for the fear of divulging its secrets. As succinctly put by Oguamanam, et al (2018:87-88): "The Odo deity operates one of the most sophisticated secret networks that the world of traditionalism has ever known. In fact, the driving force of the Odo deity is the secrecy surrounding the procurement and manifestation of its masquerades. Secrecy is the secret of the secret cult. It is around this secret that most activities of the Odo deities hangs. Everything must be done to preserve this secret, no cost is too much, no price is too high to pay, as long as the secret is kept intact. This aspect of human sacrifice is one of the reasons Christians do not participate in masquerade administration.

\section{(d) Womanhood:}

In those communities that practice the culture of masquerade, women suffer the most in the hands of these masquerades while on performance or by its internal structures and filthy gender discriminatory contents. Examples can suffice here: It is on record that village women who are petty traders have lost their capital, profit and wares on their ways to and fro the local markets as the masquerades waylay them on the road and dispossess them of their possessions. At other instances the young ones among them have been raped within the culture that prohibits adultery very strictly. Some young girls who refuse the friendship of some boys are visited as masquerades with flogging and other violations including rape. The Opi story where an undergraduate nursing mother was raped as a response to her rejection of love advances by the masquerade lover boy is one example too many(Ozor, 2012:1). The boy violated the rules of the spirit and abused the rights of womanhood and of personal autonomy. As the culture is one of male dominance, women are insulted by night masquerades like Abere and onyek'rr who reveal their"sins" to the public. Often times, the women are innocent but due to one grievous or frivolous family misunderstanding, the husbands could inform the masquerades about the wives' perceived misdemeanor which the masquerades capitalize on to compose songs and music for public ridicule. Omabe does this public shame on women during the day. At the sight of Onyenweal', a masquerade that performs some vital rituals at the burial of the eldest man (onyishi), the woman or the girl child must eat a handful of sand as she runs away. Ugwu(1987:32) wrote that, "The most melodious of all our local orchestras is Omabe. Women are denied the right and the joy of going to the otobo to see and enjoy the Omabe orchestra. Women are ordered to cook for Omabe and Abere. Omabe's meals were some of those rare dishes in our primitive and poverty-stricken society when meat was added to the soup, yet women were forbidden to eat these delicious meals they themselves cooked once they were pronounced, after cooking, as Omabe sfood. Another popular meal for Omabe wasokpa sometimes called obubu, very sweet and nourishing cake and bread of ground-peas. 
After preparing this rare dainty, the women passed it over to their husbands for Omabe and from that moment on woman could eat it again. The result was that during the Omabe feast, men ate and drank and made merry for up to two days on meals prepared by their wives while their wives and daughters were excluded from the meals save the parts they had kept back before the food was declared Omabe's food". It is good to remark that there masquerade feasts are very heavy burdens to womanhood in very many respects.

\section{Factors Responsible for Aberrations.}

The contemporary trends highlighted above evidence that masquerade regime as an African Culture has lost its value and original positive aspects. In antiquity, masquerades had a good number of good functions across Africa which included entertainment, judicial functions of police that ensured order and discipline and morality. However, the gross abuses and the discovery of the underpinning negative dimensions of masquerades over time across Africa now prompt a down-turn appreciation index for its continued existence. As articulated by Ajayi (2015:2), "Ibadan masquerade festival had always left on its trail tears, losses, violence, bloodshed and even death in some cases". One can identify the following factors as responsible for the aberrations seen today in masquerade administration in Africa. They include:

(i) Neo-paganism: Some fallen Christians or the weak ones advertise the erroneous belief that Christianity is a foreign religion and as a consequence should not be allowed to displace the African culture (omenala) like masquerade (itimmanwu, imema). In this group are found literates, unconverted but baptized Christians, politicians and wealthy but non-Christian members of the society. They encourage masquerade regime with their wealth and confused tongues with which they corrupt the young.

(ii) Bad Economy: The economy of most African countries is bad. Now and again, International rating bodies speak of African continent as poverty-stricken. The situation in Nigeria, for instance, is that there is poverty in the land; young men are forced to take the bitter pills of unemployment. Some of them engage in "stop and donate" masquerade to get their daily bread. The ethical evaluation of this reason is found wanting because the end does not justify the means and moreover, there are many legitimate means which one can engage in other than broad day light masked robberies in the name of culture.

(iii) Materialism: The adage: "The love of having grows by having "(Latin: Amorhabendihabendocrescit) captures the spirit of unbridled quest for materialism. The materialist worships the god of matter and he/she does not know when enough is enough with material acquisitions. In order to continue in political relevant circles, and sustain some level of fame and wealth, some unscrupulous members of the political class apply young men to whatever activities that would make them loyal in the eyes of their god-fathers. One of such activities is masquerade-sponsorship. One dimension to this interaction is that these young men succumb to be used for thuggery, rigging and other obnoxious practices during elections. This explains why they are not arrested, and even if arrested, are released with flimsy excuses.

(iv) Peer-group syndrome: Some youths who engage in masquerade are lured into it by their friends and colleagues within their circle of circulation. They do the forbidden because they were not initiated into the cult. They, culpably, do not know the rules. Some of them have neither paternal nor maternal affiliations with masquerade nor are the from the cultural zone that owns the masquerade. So they have no rights to membership. Again, the push from drugs or alcohol as they drink every intoxicating liquid and smoke every brain-disorganizing grasses and leaves make them step on people's rights. It is unfortunate that some of these boys are rom Christian homes to the shocking embarrassments of their parents and parishes.

\section{Pastoral Considerations}

Masquerade does not belong to the core values of Christian religion. In the words of Bishop Okobo (2010:33-34), "Nsukka zone has lots of feasts and festivals celebrated in various forms and degrees in different towns and villages. Cultural performances and masquerades feature prominently in most of these festivals, not just for entertainments, but by way of giving expression to the cultural, social and religious values of the people. This explains why many people are sentimentally attached to these festivals, and readily rise in defence of masquerades. Though masquerades were also used in traditional societies for security and maintenance of order, they were primarily designed to advance the course of African Traditional Religion. Even when people engage in them without being conscious of their religious connotations, they nonetheless invoke the religious values of the African Traditional Religion. Some of these unfortunately conflict with the Christian message. 
Prominent among them are the use of charms and violence, appeal to occult world and perpetration of deception". One of the core fundamentals of Christian doctrine is the incarnation articulated in Johannine Christology thus: EtVerbumcarofactumest, ethabitavitinnobis - And the Word took flesh and dwelt among us ( John 1:14).

Christ became man so that humanity can understand God but in masquerade culture, men became gods so as to be misunderstood. The misunderstanding begins already with deceit and pretenses that the masked persons are spiritual beings from the land of the dead. The Pauline Kenosis (Phil. 2:1-11) is all about Jesus' humanity, the Emmanuel and Christ (Matthew 1:23) and God has visited his people (Luke 1:68, 7:16). The Christmas masquerades (Mmonwu Christmas) may have entertainment value during this great feast of the Word-Incarnate but are not officially Christian.

\section{Recommendations}

In very many respects, masquerade culture has turned into a social menace. The excesses cannot be contained any more. The young men and adults who engage in it have to be de-schooled in order to embrace good moral and societal values. In order to achieve greater safety of human rights for all, we recommend as follows:

1. The Holy Mother Church should continue to in her important dialogue with African Traditional Religion according to the provisions of Nostra Aetate.

2. The youths who engage in masquerade cult need to be guides properly through value re-orientation by the government and by proper catechesis by the Church for her members who stray into masquerading enterprises.

3. The civil government should ban any masquerades that violate the rights or human beings. On this note Bishop Onah (2017:2) said, " The security agents should treat these criminals who hide under the guide of masquerade as a culture to harass and harm law-abiding citizens as terrorists and cultists". All masquerades on the major roads that disturb people's freedoms even if temporarily should be arrested and prosecuted. Those who engage in criminal activities like robbery, rape flogging and torturing people, arson etcetera, should be made to face the full wrath of the law.

4. Traditional institutions and rulers should be awake to their responsibilities and regulate masquerade practices, if it must continue, to ensure that are social justice and peace.

5. Parents should step up and live the good ideals of Christian homes that eschew idolatry so that their children would emulate their good examples.

6. The masquerades that appear during Christmas, Easter or any other Christian festivals do not satisfy as any evidence of inculturation. Therefore there is need for deeper studies of this phenomenon according to cultural zones and the masquerades by their nature and purpose.

\section{Conclusion}

Masquerades have challenges today across Africa due to the influences of Christianity, urbanization and westernization. The emergence of these new civilizations based on new discoveries, new Faith in Christ, heterogeneous socio-cultural patterns suffocate the thriving of the hitherto appreciated masquerade culture. What is vivid is that the homogeneity of time-structure and social relations cannot fit into contemporary systems without clashes of civilizations. People move in different directions in pursuit of various legitimate interests which cannot bow to masquerade regimes. The greatest undoing of masquerade institution is its abuse of human rights. Any cultural practice that projects the worship of false gods, applies violence and erodes the dignity of the human person cannot but be jettisoned to the refuse bin of history.

\section{References}

Chukwudozie, C.N.(1999). Introduction to HumanRightsandSocial Justice, Owerri: Cape Publishers.

Bishop F.E.O. Okobo (2010).Instrumentum Laboris for the First Nsukka Diocesan Synod, Nsukka: Social Communications.

Ajayi, O. (2015). "Police arrest Masquerade; 2 Others with human parts" in vanguardngr.com, https://www.vanguardngr.com/2015/06/police-arres, Retrieved, 24/1o/2018.10:07 AM

Adegun, A.(2017) Reports Bishop Godfrey Onah's Response to "Abomination as Masquerade beats seminarian to coma in Nsukka" in https://www.legit.ng/1097234-abomination-masque.., Retrieved,24/10/2018, 10:03 AM.. 
.Ozor, C. (2015).“ Masquerades on the Rampage in Nsukka” in Vanguardngr ,https://www.vanguardngr.com/ 2015/masquerade. Retrieved, 24/10/2018. 9:51 AM

.Oguamanam, C.C., et al. (2018).Odo Masquerade in Northern Igbo Land: A cultural Resource in Demise in JournalofTourismandHeritageStudies, Vol. 7, No.1.

.Ukwu, J., (2017) "Police detain 10 masquerades in Akwa Ibom" in https://www.legit.ng/1078958-police-detain10-masquerades-akwa-i, Retrieved, 24/10/2818, 10;12AM.

.Adama, T.(2013).'Igala Masquerades as Agent of Moral and Social Transformation" in Bassey And ahJournal, Vol.6.

.nationalhelm.co (2018) "Two Catholic Priests Beaten Mercilessly by Masquerades in Enugu" in https://www.nationalhelm. co/2018/07/two-nsukka-c. Retrieved 24/10/2018, 10:05 AM.

Ozioko, M.A.(2005) Obukpa: PastandPresent, De-Adroit Innovation.

.Ugwu, D.C.(1987). ThisisObukpa. AHistoryofTypical AncientIg bo State, Enugu: Fourth Dimension Publishers.

Ozor, C.(2012)Masquerade Rapes Undergraduate Nursing Mother in Opi” in Vanguard News, https://www.vanguardngr.com. Retrieved, 26/10/2018, 1:12 PM.

The New Jerusalem Bible, Standard Edition (2013).New Delhi: Alberione Good NewsCentre. Constitution of the Federal Republic of Nigeria, 1999 As Amended, Chapter IV, in www..nigeria-law.org, Constitution of Th.., retrieved, 26/10/2018, 2:14 PM. 